\title{
College student food insecurity and its relationship to fruit and vegetable intake and overweight/obesity at a $\mathrm{HBCU}$
}

\begin{abstract}
Background: Food insecurity has been a very prominent, but understudied topic among U.S. colleges. African-American college students have been shown to be the group most impacted by food insecurity. There has been some evidence of association between food insecurity and low fruit and vegetable consumption, as well as with increased fast food consumption and overweight/obesity.
\end{abstract}

Methods: A convenience sample of 10,300 students attending a historically black college /university (HBCU) were invited to complete an online survey with questions that measured food security using the United States Department of Agriculture Adult Food Security Survey Module (USDA-AFSSM), body mass index (BMI), the frequency of fruit and vegetable intake, and fast food purchases. A cross-sectional study was conducted to assess the relationships between the variables and the food security status of the participants at $5 \%$ significant.

Results: The students who experienced some level of food insecurity were found to have lower consumption of fruits and vegetables and on a weekly basis were more likely to purchase fast food meals compared to food secure students. There was no significant difference in the BMIs of food secure vs food insecure student.

Conclusion/recommendations: The present study showed that food insecure students were significantly more likely to purchase fast foods compared with food secure students. Further research is needed to attain a more comprehensive understanding of the depth of prevalence of food insecurity among students attending HBCUs and its effect on food choices and obesity risk.

Keywords: HBCU, student, food insecurity, nutrition, fruits, vegetables, fast food
Volume 8 Issue 3 - 2018

\author{
Linda L Thompson,' LN Rajae Gayle, ${ }^{2}$ \\ Chimene Castor ${ }^{2}$ \\ 'Assistant Professor, Department of Nutritional Sciences, \\ College of Nursing and Allied Health, Howard University, USA \\ ${ }^{2}$ Department of Nutritional Sciences, College of Nursing and \\ Allied Health, Howard University, USA
}

Correspondence: Linda LThompson, Assistant Professor, Department of Nutritional Sciences, College of Nursing and Allied Health, Howard University, Email linda.thompson@howard.edu

Received: June 17, 2018 | Published: June 21, 2018
Abbreviations: USDA-AFSSM, United States department of agriculture adult food security survey module; BMI, body mass index; HBCU, historically black college /university

\section{Introduction}

The United States Department of Agriculture/Economic Research Service (USDA/ERS), defines food security as the access by all people, at all times, to a safe and adequate diet for an active and healthy life. ${ }^{1,2}$ Food insecurity has been found to be prevalent among AfricanAmerican communities due to low incomes, low levels of education, high rates of unemployment, and food deserts. ${ }^{1,2}$ Research has found that an estimated one in five (22.5\%) African-American households is food insecure whereas, one in eleven (9\%) of White households is deemed food insecure..$^{3-6}$ An estimated one in four (26\%) of AfricanAmerican children is living in a food-insecure household compared to one in eight $(13 \%)$ white children. ${ }^{3-6}$

College students (both undergraduate and graduate students) also experience food insecurity. An examination of food security at the University of California (UC) campuses revealed a prevalence of low and very low food insecurity of $25 \%$ and $23 \%$ respectively within the past 12 months. ${ }^{7}$ Moreover, studies have shown that food insecurity is 1.5 times higher among Black and Hispanic students when compared to White and Asian students. ${ }^{8}$ Data is scarce regarding food security and students attending historically black colleges and universities (HBCUs).

Research, particularly in the United States and Canada, has illustrated that food insecurity is associated with poor health and nutrition outcomes, poor psychological and cognitive functioning, substandard academic achievement and an increased risk of chronic diseases such as overweight/obesity and malnutrition..$^{3-6}$ In contrast, consuming lots of fruits and vegetables has been shown to be good for optimal health. ${ }^{4,5}$ The micronutrients that are obtained from fruits and vegetables have been associated with reducing cancer, cardiovascular risk, stroke, diverticulitis, cataract, macular degeneration and the control of both blood pressure andcholesterol. ${ }^{6,8}$ Deficiencies in micronutrients have been shown to be linked to a higher risk of overweight/obesity. ${ }^{3-6}$

Food insecurity has been found to be a risk factor in chronic disease and associated with chronic disease prevalence. ${ }^{9}$ Among the food insecure, associations have been reported with diabetes and cardiovascular disease. ${ }^{10-12}$ Persons who are food insecure often have difficulty in managing their chronic disease, as they are challenged to follow disease-related dietary protocol. ${ }^{9,13}$

This study assessed the level of food insecurity among students attending a large $\mathrm{HBCU}$; fast food consumption among the food 
insecure; and whether students who are shown to be food insecure are also at risk for obesity and for low intakes of fruits and vegetables.

\section{Methods}

The study was a cross-sectional descriptive survey that utilized a non- probability sample. Inclusion criteria for participants were that students must be 18 years or older, currently be enrolled at the HBCU and have access to the University e-mail system. Students under 18 years of age were excluded. Both undergraduate and graduate students were recruited. Data were collected via a 20 -item survey using Qualtrics, an online software program that allows its users to create and distribute survey instruments.

Upon the university's Institutional Review Board approval, the survey instrument was distributed by the university's office of communications. An announcement was sent to students by email informing them of the survey with a link to access it. The survey was also advertised by university social media platforms: Facebook, Instagram, and Groupme and an announcement of the survey were sent out once per week for 4 weeks. Participants had an opportunity to win a $\$ 50$ gift certificate to a supermarket if they participated in the survey.

Survey questions were derived from multiple sources which include the Six-item United States Department of Agriculture-Adult Food Security Survey Module (USDA-AFSSM). Additionally, questions were taken from the "Food Pantry Needs Survey for Students", a college campus food security survey (Student Government Toolkit, 2015) and another validated instruments which assessed food insecurity among college freshmen. ${ }^{8}$ Information on students' weights and heights was gathered from the survey participants in order to calculate each student's body mass index (BMI) using the formula weight $(\mathrm{kg}) \div$ height $^{\wedge} 2(\mathrm{~m})$ to determine weight status. The survey also included questions which measured fruit and vegetable consumption and daily fast food purchases.

\section{Results}

Out of approximately 10,000 who had access to the announcement of the survey, a total of 570 students participated. Forty-nine survey participants were disqualified for either not completing the survey or for not providing sufficient data to determine food security status. The final sample size was 521 students yielding a 5.1\% student response rate.

\section{Prevalence of food insecurity and characteristics of food insecure students}

After assessing the participants' AFSSM scores using the sixitem survey module, it was found that $77.7 \%$ (405) of the sample had experienced some level of food insecurity over the last 12 months, whereas $116(22.2 \%)$ were determined to be food secure. The prevalence of the four categories of food security status is shown in Figure 1. It was determined that $10.9 \%$ (57) experienced high food security, $11.3 \%$ (59) experienced marginal food security, $26.1 \%$ (136) experienced low food security and $51.6 \%$ (269) experienced very low food security over the last 12-month time-period.

The USDA defines the four levels of food security in the following way: "high food security-no reported indications of food-access problems or limitations; marginal food security-one or two reported indications-typically of anxiety over food sufficiency or shortage of food in the house. Little or no indication of changes in diets or food intake; low food security-reports of reduced quality, variety, or desirability of diet. Little or no indication of reduced food intake; very low food security-reports of multiple indications of disrupted eating patterns and reduced food intake." Independent sample t-tests were conducted to compare the fruit and vegetable intakes of food secure and food insecure students. (Table 1) shows that significant differences in fruit and vegetable intakes were found between food secure and food insecure students $(\mathrm{p}=0.000)$. Food insecure students had significantly lower mean fruit and vegetable intakes than food secure students.

Table I Fruit and vegetable intake by food security status

\begin{tabular}{lll}
\hline Variables & $\begin{array}{l}\text { Food secure } \\
\text { mean } \pm \text { SEM }\end{array}$ & $\begin{array}{l}\text { Food } \\
\text { secure } \\
\text { mean } \pm S E M\end{array}$ \\
\hline $\mathrm{N}$ & 107 & 384 \\
Fruit Intake (number of servings) & $1.85 \pm 0.12^{\mathrm{a}}$ & $1.51 \pm 0.09^{\mathrm{b}}$ \\
$\mathrm{N}$ & 107 & 383 \\
$\begin{array}{l}\text { Vegetable Intake (number of } \\
\text { servings) }\end{array}$ & $1.83 \pm 0.1 \mathrm{I}^{\mathrm{a}}$ & $1.77 \pm 0.09^{\mathrm{b}}$ \\
\hline
\end{tabular}

Note: a,b Means with different letters as superscript are significantly different $(p<0.05)$.

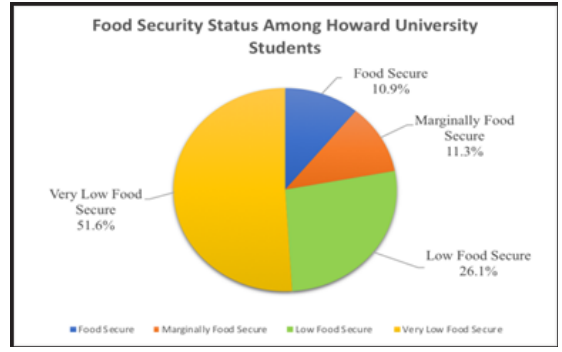

Figure I Pie chart showing the percentage of each level of food security with the study sample.

Table 2 shows that of the students who were overweight $(n=144)$ or obese ( $\mathrm{n}=83$ ), the overwhelming majority were food insecure (79.2\% and $80.7 \%$ respectively). A significant association was not found between food security status and BMI status (chi-square statistic $=1.084, \mathrm{p}=0.781)($ Table 3$)$.

The relationship between fast food purchases and food security status was significant (chi-square statistic $=20.988, \mathrm{p}=0.000$ ). Food insecure students were significantly more likely to purchase fast foods two or more times a week (85.2\% or more), compared with food secure students ( $14.8 \%$ or less) (Table 4$)$.

Table 2 Participant BMI classifications by food secure status

\begin{tabular}{|c|c|c|c|}
\hline Variables & $\begin{array}{l}\text { Food secure } \\
\text { students } \\
\text { n (\%) }\end{array}$ & $\begin{array}{l}\text { Food insecure } \\
\text { student's n (\%) }\end{array}$ & $\begin{array}{l}\text { Total } \\
\text { students } \\
(\%)\end{array}$ \\
\hline \multicolumn{4}{|l|}{ BMI Status } \\
\hline Underweight I & 5 (26.3\%) & I 4 (73.7\%) & $19(100 \%)$ \\
\hline $\begin{array}{l}\text { Normal } \\
\text { weight } 2\end{array}$ & $54(23.8 \%)$ & I 73 (76.2\%) & $227(100 \%)$ \\
\hline Over weight3 & $30(20.8 \%)$ & II4 (79.2\%) & I 44 (100\%) \\
\hline Obese4 & $16(19.3 \%)$ & 67 (80.7\%) & $83(100 \%)$ \\
\hline
\end{tabular}

Note: Counts will not always sum to 521 because of missing data from individual survey responses. 
Table 3 Participant BMI classifications by food secure status

\begin{tabular}{ll}
\hline Number of participants & BMI \\
\hline I & $18.5 \mathrm{~kg} / \mathrm{m}^{2}$ \\
218.5 & $24.9 \mathrm{~kg} / \mathrm{m}^{2}$ \\
325 & $29.9 \mathrm{~kg} / \mathrm{m}^{2}$ \\
4 & $30.0 \mathrm{~kg} / \mathrm{m}^{2}$ or higher \\
\hline
\end{tabular}

Table 4 Participant fast food purchase frequency by food secure status

\begin{tabular}{llll}
\hline Variables & $\begin{array}{l}\text { Food secure } \\
\text { students n (\%) }\end{array}$ & $\begin{array}{l}\text { Food } \\
\text { insecure } \\
\text { students } \\
\text { n (\%) }\end{array}$ & $\begin{array}{l}\text { Total } \\
\text { students } \\
\text { n (\%) }\end{array}$ \\
\hline Fast Food Purchases & & $165(70.2 \%)$ & $\begin{array}{l}235 \\
(100 \%)\end{array}$ \\
Once/week & $70(29.8 \%)$ & $98(85.2 \%)$ & $\begin{array}{l}115 \\
(100 \%)\end{array}$ \\
Twice/week & $17(14.8 \%)$ & $77(88.5 \%)$ & $87(100 \%)$ \\
Three times/week & $10(11.5 \%)$ & $20(87.0 \%)$ & $23(100 \%)$ \\
Four times/week & $3(13.0 \%)$ & $20(90.9 \%)$ & $22(100 \%)$ \\
$>$ Four times/week & $2(9.1 \%)$ & &
\end{tabular}

Note: Counts will not always sum to 521 because of missing data from individual survey responses.

\section{Discussion}

The prevalence of food insecurity was determined to be $77.7 \%$. The results of this study are consistent with findings of studies which reported food insecurity levels greater than $50 \%{ }^{14,15}$ Food insecurity was nearly six times that reported for American households by the US Department of Agriculture (USDA) as well as for the state of District of Columbia for the year of $2016(12.3 \% \& 11.4 \%$ respectively $) .{ }^{3-6}$ The prevalence of food insecurity found in this study is consistent with previous studies that have determined food insecurity rates among college students to be higher than the national average. ${ }^{10,16-19}$

The mean fruit and vegetable intakes of food insecure students were significantly lower than those of food secure students (Table 3 ). These results are consistent with previous studies which provided evidence of lower fruit and vegetable consumption among food insecure students ${ }^{6,19}$ The most common intake levels among the sample were between 0-3 servings/day among those classified as food insecure (95\% for fruits and $94.2 \%$ for vegetables). Overall, the mean intakes of fruits and vegetables were below recommended numbers of servings of fruits and vegetable of five or more a day (at least 2 servings of fruit and at least 3 servings of vegetables each day). ${ }^{20,21}$

With reported negative perception of nutrient dense fruits and vegetables as being less satisfying and less value for money when compared to energy dense foods, this mentality may impact the consumption levels among the food insecure student ${ }^{6}$ Further investigation should be conducted to assess students' accessibility to fruits and vegetables throughout the academic year. The cost of perishable food items such as fruits and vegetables may also play a role in the intake levels wherein students cannot afford to purchase fresh produce on a weekly basis to fulfill their dietary needs.

As shown in Table 3 BMI status was found to have no significant association with food security status. These results are consistent with a study with finding from other studies ${ }^{14,15}$ which found no relationship between food security status and BMI. The present study showed that food insecure students were significantly more likely to purchase fast foods compared with food secure students (Table 3). Similarly, studies found that students attending the University of Texas San Antonio which highlighted the fact that fast food consumption is a significant part of the college experience..$^{21}$ Contributing reasons for consumption include students feeling that purchasing fast food is more convenient, less time consuming, and is accessible for purchase. ${ }^{14,15}$ The level of accessibility to and cost of fast food meals from various restaurants in the area surrounding the HBCU may play a contributing role as to why students end up making more frequent fast food purchases, which is high in calories, fat and sodium. ${ }^{15-21}$

The study had several limitations that may have influenced the assessment of food security and its association with fruit and vegetable intake and overweight/obesity. The study overall had a low response rate $(5.1 \%)$. Low response rates, particularly for webbased surveys are acknowledged as a limitation in other studies. ${ }^{4-7}$ All data collected were self-reported and this could have increased the likelihood of response bias to questions, for example, asking about weight and height.

\section{Recommendations/implications for future research}

Further research is needed to attain a more comprehensive understanding of the depth of prevalence of food insecurity among students attending HBCUs. Research at HBCUs that explore food security status, academic performance and overall student health, can help develop policies and student supports that lead to increased student food security and possibly improved student retention. In addition, providing an on campus student food pantry can be a strategy to help address food insecurity.

\section{Acknowledgments}

None.

\section{Conflict of interest}

Author declares no conflict of interest.

\section{References}

1. USDA-AFSSM. Definitions of Food Security.

2. USDA-ERS. Household Food Security in the United States in 2016.

3. Coleman Jensen A, Rabbitt MP, Gregory CA, et al. Household food security in the United States in 2015. Economic Research Service. 2016. $44 \mathrm{p}$.

4. Coleman Jensen A, Rabbitt MP, Gregory C, et al. Statistical Supplement to Household Food Security in the United States in 2016. Administrative Publication. 2017;33.

5. Gallegos D, Ramsey R, Ong KW. Food insecurity: is it an issue among tertiary students? Higher Education. 2014;67(5):497-510.

6. Murimi MW, Kanyi MG, Mupfudze T, et al. Prevalence of food insecurity in low-income neighborhoods in West Texas. Journal of nutrition education and behavior. 2016;48(9):625-630.

7. Laraia BA. Food insecurity and chronic disease. Adv Nutr. 2013;4(2):203212.

8. Gucciardi E, Vogt JA, De Melo M, et al. Exploration of the relationship between household food insecurity and diabetes in Canada. Diabetes Care. 2009;32(12):2218-2224 
9. Fitzgerald N, Segura-Pérez S, Pérez-Escamilla R. Food insecurity is related to increased risk of type 2 diabetes among Latinas. Ethn Dis. 2011;21(3):328-334.

10. Seligman HK, Laraia BA, Kushel MB. Food insecurity is associated with chronic disease among low-income NHANES participants. $J$ Nutr. 2010;140(2):304-310.

11. Berkowitz SA, Berkowitz TSZ, Meigs JB, et al. Trends in food insecurity for adults with cardiometabolic disease in the United States: 2005-2012 PLoS One. 2017;12(6):e0179172.

12. Freudenberg N, Manzo L, Jones H, et al. Food insecurity at CUNY: Results from a survey of CUNY undergraduate students. Campaign for a Healthy CUNY, New York, NY, 2011.

13. Patton-López MM, López-Cevallos DF, Cancel-Tirado DI, et al. Prevalence and correlates of food insecurity among students attending a midsize rural university in Oregon. Journal of nutrition education and behavior. 2014;46(3):209-214.

14.US Department of Agriculture. Food Security in the U.S. 2016.

15. Azagba S, Sharaf MF. Disparities in the frequency of fruit and vegetable consumption by socio-demographic and lifestyle characteristics in Canada. Nutrition journal. 2011;10(1):118.
16. Biediger-Friedman L, Sanchez B, He M, et al. Food Purchasing Behaviors and Food Insecurity among College Students at The University of Texas at San Antonio. Journal of Food Security. 2016;4(3):52-57.

17. Bruening M, Argo K, Payne-Sturges D, et al. The Struggle Is Real: A Systematic Review of Food Insecurity on Postsecondary Education Campuses. Journal of the Academy of Nutrition and Dietetics. 2017;117(11):1767-1791.

18. Farahbakhsh J, Hanbazaza M, Ball GD, et al. Food insecure student clients of a university-based food bank have compromised health, dietary intake and academic qualit

19. y. Nutrition \& Dietetics. 2017;74(1):67-73.

20. Student Government Toolkit. Running a food campus pantry.

21. Van den Berg L, Raubenheimer J. Food insecurity among students at the University of the Free State, South Africa. South African Journal of Clinical Nutrition. 2015;28(4):160-169.

22. FSIN. Global report on food crises. 2017. 